\title{
Inhibition of pro-collagen I expression by oxymatrine in hepatic stellate cells is mediated via nuclear translocation of Y-box binding protein 1
}

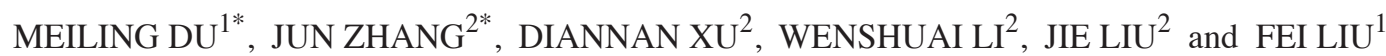 \\ ${ }^{1}$ Department of Digestive Diseases, Shanghai East Hospital, Tongji University, Shanghai 200120; \\ ${ }^{2}$ Department of Digestive Diseases, Huashan Hospital, Fudan University, Shanghai 200040, P.R. China
}

Received December 20, 2014; Accepted September 10, 2015

DOI: $10.3892 / \mathrm{mmr} .2015 .4428$

\begin{abstract}
Accumulating evidence indicated that oxymatrine (OMT), an alkaloid compound from the Chinese medicinal herb Sophora flavescens, exhibits activity against hepatic fibrosis. The present study attempted to explore the underlying mechanisms of OMT-mediated inhibition of collagen production. For this, the LX-2 human hepatic stellate cell line was treated with OMT (240, 480 or $960 \mathrm{mg} / \mathrm{l})$ for 3-5 days. The endogenic expression of pro-collagen I was decreased by OMT in a dose- and time-dependent manner, accompanied with the downregulation of Y-box binding protein 1 (YB-1), a vital transcription factor, particularly on the fourth day of incubation with a high concentration of OMT. To further explore the intracellular changes in YB-1 levels, nuclear/cytoplasmic proteins were extracted separately, and subsequent western blot analysis revealed a significant upregulation of YB-1 in the nucleus in parallel with its downregulation in the cytoplasm, indicating the nuclear translocation of YB-1 induced by OMT treatment. In another experiment, knockdown of YB-1 using small interfering RNA led to elevated mRNA levels of collagen I, thereby reversing the effects of OMT treatment. In conclusion, these present study suggested that the attenuation of pro-collagen I expression caused by OMT was, to a certain extent, mediated via nuclear translocation of YB-1.
\end{abstract}

Correspondence to: Dr Fei Liu, Department of Digestive Diseases, Shanghai East Hospital, Tongji University, 150 Jimo Road, Shanghai 200120, P.R. China

E-mail: liufeiguo2010@163.com

Dr Jie Liu, Department of Digestive Diseases, Huashan Hospital, Fudan University, 12 Middle Wulumuqi Road, Shanghai 200040, P.R. China

E-mail: jieliu@fudan.edu.cn

*Contributed equally

Key words: oxymatrine, Y-box binding protein 1, hepatic fibrosis, nuclear translocation

\section{Introduction}

Y-box binding protein 1 (YB-1), a member of the highly evolutionarily conserved Y-box family, has an important role in cell physiological activities, including gene transcription (1-3), translation $(4,5)$, damage repair and cancer drug resistance (6,7). It consists of three principal domains (Fig. 1): i) The $\mathrm{N}$-terminal domain, also termed the $\mathrm{A} / \mathrm{P}$ domain, is rich in alanine and proline and involved in transcriptional regulation. ii) The middle part is the cold shock domain (CSD), a highly conserved sequence, which performs the core function, i.e., it binds to the Y-box, an inverted CCAAT box in the promoter of numerous specific genes, including major histocompatibility complex class II, multi-drug resistance gene 1 as well as cyclin A and B1 (8-10). iii) An elongated C-terminal domain, containing alternating clusters of positively and negatively charged amino-acid residues, which is implicated in protein-protein interactions and serves as a pivotal signaling peptide during nuclear translocation (11).

Several studies have reported that CSD is implicated in the regulation of the transcription of the $\alpha 1$ - and $\alpha 2$-strands of collagen I [COL $\alpha 1(\mathrm{I})$ and COL $\alpha 2(\mathrm{I})]$, which are intrinsically linked to the development of hepatic fibrosis (12). Type I collagen is a heterotrimer composed of two $\alpha 1$-strands and one $\alpha 2$-strand. YB-1 was reported to suppress the transcription of the COL $\alpha 1(\mathrm{I})$ gene via binding to collagen Y-box element or transforming growth factor (TGF) $-\beta$ response element in the promoter of COL $\alpha 1$ (I) $(13,14)$. Furthermore, YB-1 was confirmed to be involved in interferon- $\gamma$ (IFN- $\gamma$ )-induced downregulation of the COL $\alpha 2$ (I) gene (15) through binding to the IFN- $\gamma$-responsive element in the promoter of COL $\alpha 2$ (I) (16).

YB-1 regulates pro-collagen I expression in the nucleus only; therefore, nuclear translocation of YB-1 is essential for it to exert its function. Agents with the ability to promote the nuclear translocation of YB-1 may have beneficial effects on hepatic fibrosis. In previous studies, p53 (17), ultraviolet irradiation (18) and the small molecule $\mathrm{HSc025}$ (19) were demonstrated to enhance the nuclear translocation of YB-1.

Oxymatrine (OMT) is the major active component of the Chinese medicinal herb Kushen, which is the dried root of Sophora flavescens. The anti-viral (20), anti-oxidative $(21,22)$, anti-fibrotic (23) and immunoregulatory 
effects $(24,25)$ of OMT have been demonstrated in numerous studies $(20,21,23-25)$. At present, OMT is widely applied in the clinic to protect the liver from fibrosis.

The present study assessed whether OMT may exert its long-known effects against hepatic fibrosis via promoting the nuclear translocation of YB-1 to suppress the production of pro-collagen I. The present study considerably enhanced the current understanding of the underlying mechanism of the anti-fibrotic effects of OMT.

\section{Materials and methods}

Cell culture. The LX-2 human hepatic stellate cell (HSC) line (Shanghai Fuxiang Biotechnology Co., Ltd, Shanghai, China), was cultured in Dulbecco's modified Eagle's medium (DMEM; Invitrogen; Thermo Fisher Scientific, Waltham, MA, USA) supplemented with $10 \%$ fetal bovine serum (FBS; Invitrogen) and kept in an incubator containing $5 \% \mathrm{CO}_{2}$ at $37^{\circ} \mathrm{C}$. The cells were sub-cultured every 3-4 days.

Drug treatment. OMT (BOC Sciences, New York, NY,USA) was dissolved in complete medium to produce a stock solution. Prior to use in the assays, cells were synchronized by serum-starvation for $24 \mathrm{~h}$. Cells $\left(5 \times 10^{5}\right)$ were then seeded into $60 \mathrm{~mm}$ dishes. Subsequently, OMT solution was added to generate a series concentrations of OMT (240, 480 and $960 \mathrm{mg} / \mathrm{l})$. Furthermore, a control group without OMT treatment was established. The cells were incubated for 3-5 days prior to analysis.

Reverse-transcription quantitative polymerase chain reaction (RT-qPCR) analysis. RNA from LX2 cells was extracted by using TRI Reagent ${ }^{\circledR}$ (Sigma-Aldrich, St. Louis, MO, USA) according to the manufacturer's instructions. cDNA was synthesized from $1 \mu \mathrm{g}$ RNA using the FastQuant RT kit (Tiangen, Beijing, China) according to the manufacturer's protocol. Real Time PCR mixtures $(10 \mu \mathrm{l})$ were then prepared in triplicate, each containing $1 \mu \mathrm{l}$ cDNA template, $5 \mu 1$ of SYBR ${ }^{\circledR}$ Premix Ex Taq (TaKara, Japan), 0.2 ul of ROX Reference Dye II (Takara Bio, Inc., Otsu, Japan), $0.2 \mu \mathrm{l}$ primer (10 mM; Genewiz, Inc., Suzhou, China), and $3.6 \mathrm{ml}$ DEPC-treated water. Primers were as follows: COL $\alpha 1(\mathrm{I}), 5^{\prime}$-CATGTTCAGCTTTGTGGACC-3' (forward) and 5'-TTCTGTACGCAGGTGATTGG-3' (reverse); COL $\alpha 2$ (I), 5'-TGCTGCTCAGTATGATGGAAA-3' (forward) and 5'-CAGGTCCTTGGAAACCTTGA-3' (reverse); YB-1, 5'-TCGCCAAAGACAGCCTAGAGA-3' (forward) and 5'-TCT GCGTCGGTAATTGAAGTTG-3' (reverse); $\alpha$-SMA, 5'-AGC AGTTGTAGCTACCCGCC-3' (forward) and 5'-CACGAT GGACGGGAACAC-3' (reverse). GAPDH, 5'-GAAGGTGAA GGTCGGAGTC-3' (forward) and 5'-GAAGATGGTGAT GGGATTTC-3' (reverse). cDNA samples were amplified in an Applied Biosystems 7500 Real-Time PCR system (Thermo Fisher Scientific). The thermocycling conditions included initial denaturation at $95^{\circ} \mathrm{C}$ for $30 \mathrm{sec}$, followed by 40 cycles of $95^{\circ} \mathrm{C}$ for $5 \mathrm{sec}$ and $60^{\circ} \mathrm{C}$ for $34 \mathrm{sec}$. Finally all quantified values were normalized to the endogenous GAPDH control. Gene expression levels were analyzed using the $\Delta \Delta \mathrm{Ct}$ method (26).

Transient transfection. LX2 cells in $60 \mathrm{~mm}$ cell culture dishes without serum were cultured to $\sim 50 \%$ confluence on the second day. The cells were transiently transfected with
300 pmol small interfering (si)RNA (Gene Pharma, Shanghai, China) targeting YB-1 (siYB-1) or negative control siRNA (NC) mixed with $15 \mu 1$ Lipofectamine 2000 (Invitrogen) at $6 \mathrm{~h}$ prior to treatment with $960 \mathrm{mg} / \mathrm{l}$ OMT. Cells were harvested after incubation for four days. The siYB-1 sequence was UGA CACCAAGGAAGAUGUATT and the NC sequence was UUCUCCGAACGUGUCACGUTT.

Nuclear/cytoplasmic extraction and western blot analysis. Nuclear and cytoplasmic proteins were separated using the Nuclear and Cytoplasmic Protein Extraction kit (Beyotime Institute of Biotechnology, Shanghai, China). The separation procedure was performed with caution to avoid contamination of the nuclear protein in the pellet with cytoplasmic extract.

Cytoplasmic and nuclear extracts and total protein samples were quantified using a Bichinchoninic Acid Protein assay kit (Beyotime Institute of Biotechnology, Shanghai, China) and then mixed with $4 \mathrm{X}$ Protein SDS-PAGE loading buffer (Takara Bio, Inc.) at $100^{\circ} \mathrm{C}$ for $20 \mathrm{~min}$. Proteins were separated on 10-15\% SDS-PAGE (Invitrogen; Thermo Fisher Scientific) and transferred onto polyvinylidene Fluoride membranes (EMD Millipore, Billerica, MA, USA). Following blocking with Tris-Buffered Saline and Tween 20 (TBST) with $5 \%$ fat-free milk, the membranes were incubated with the following primary antibodies overnight at $4^{\circ} \mathrm{C}$ : Anti- $\alpha$-smooth muscle actin ( $\alpha$-SMA; cat. no. ab32575), anti-extracellular signal-regulated kinase 1 and 2 (ERK1/2; cat. no. ab17942), anti-YB-1 (cat. no. ab12148; all 1:1,000; Epitomics, Burlingame, CA, USA), as well as anti-GAPDH (cat. no. ab2302) and anti-histone3 (cat. no. 2514256; both 1:1,000; Millipore, Billerica, MA, USA). The membranes were then washed with TBST for $30 \mathrm{~min}$ and incubated with secondary antibodies conjugated with horseradish peroxidase for $2 \mathrm{~h}$ at room temperature. Finally the images were captured using a gel imaging analysis system (Tanon 4100, Tanon Science and Technology Co., Ltd., Shanghai, China).

Statistical analysis. Blots were representative of three independent experiments performed in triplicate. Statistical analysis of the data was performed using Student's t-test and analyzed using SPSS software version 13.0 (SPSS, Inc., Chicago, IL, USA). Data were expressed as the mean \pm standard deviation. $\mathrm{P}<0.05$ was considered to indicate a statistically significant difference.

\section{Results}

OMT reduces the expression of endogenic type I pro-collagen. RT-qPCR analysis indicated a marked decrease in COL $\alpha 1$ (I) and COL $\alpha 2(\mathrm{I})$ gene expression following incubation with OMT (240, 480 and $960 \mathrm{mg} / \mathrm{l}$ for 3-5 days) in a dose- and time-dependent manner (Fig. 2). The high concentration of OMT $(960 \mathrm{mg} / \mathrm{l})$ was then used in the subsequent experiments.

OMT accelerates nuclear translocation of YB-1. Transcription factor YB-1 is known to inhibit pro-collagen I production (13-16). However, factors modulating the activity of YB-1 have remained to be elucidated.

The present study hypothesized that OMT inhibits the expression of pro-collagen I via facilitating the nuclear translocation of YB-1. In order to test this hypothesis, LX-2 cells were 


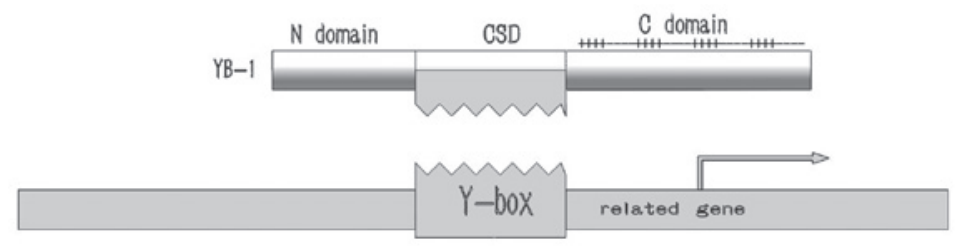

Figure 1. YB-1 is composed of three principle domains: N/C domain and CSD. The CSD, the functional part of YB-1, is able to bind to the Y-box in the promoter of specific genes, which regulates their transcription. YB-1, Y-box binding protein 1; CSD, cold shock domain.
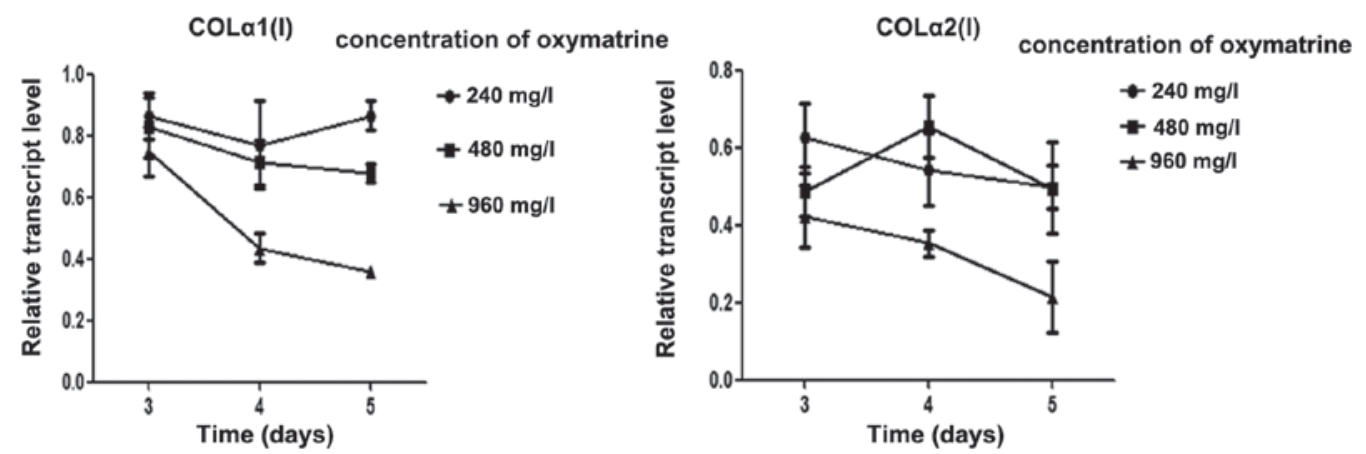

Figure 2. Reverse-transcription quantitative polymerase chain reaction analysis of COL $\alpha 1$ (I) and COL $\alpha 2(\mathrm{I})$ expression in LX-2 cells treated with oxymatrine (240, 480 or $960 \mathrm{mg} / \mathrm{l})$ for 3-5 days. Transcription of COL $\alpha 1(\mathrm{I})$ and COL $\alpha 2(\mathrm{I})$ relative to GAPDH was decreased in a dose- and time-dependent manner. COL $\alpha 1(\mathrm{I}), \alpha 1$-strand of collagen I.

A

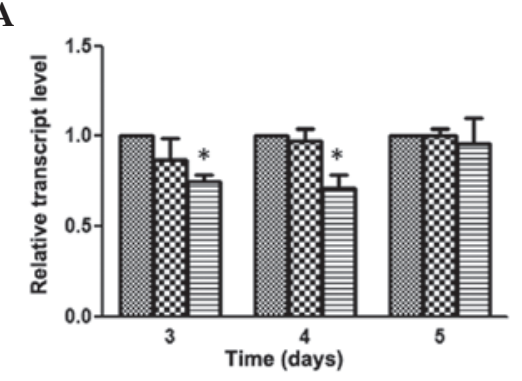

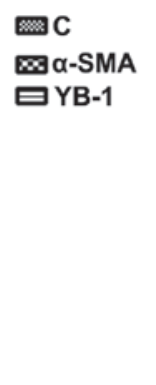

B

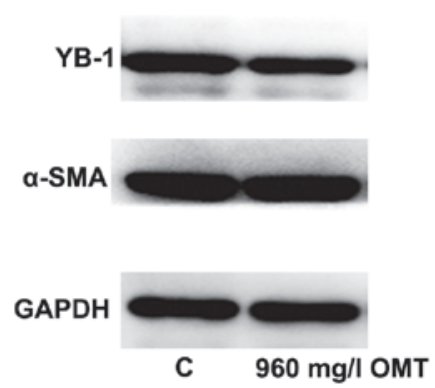

Figure 3. OMT effectively inhibits the expression of YB-1 in LX-2 cells. (A) LX-2 cells treated with OMT (960 mg/l) showed lower levels of YB-1 mRNA on the third and fourth day $(" \mathrm{P}<0.05)$ compared to those in the control group. However, $\alpha$-SMA was not significantly affected. (B) On the fourth day, total YB-1 was markedly suppressed at the protein level, while $\alpha$-SMA expression was not obviously affected. OMT, oxymatrine; SMA, smooth muscle actin; YB-1, Y-box binding protein 1; C, control.
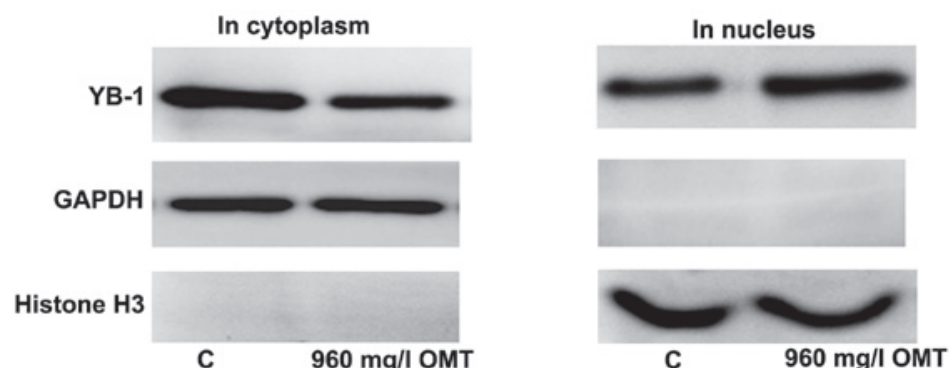

Figure 4. LX-2 cells treated with $960 \mathrm{mg} / 1$ OMT for four days showed a decrease of YB-1 in the cytoplasm and an increase of YB-1 in the nucleus, as compared with that in the control group. OMT, oxymatrine; YB-1, Y-box binding protein 1; C, control.

treated with OMT $(960 \mathrm{mg} / \mathrm{l})$, which resulted in a reduction in YB-1 expression at the transcriptional and translational level, particularly on the fourth day of incubation, while $\alpha$-SMA expression was not affected (Fig. 3). As it is well known that YB-1 regulates gene transcription in the nucleus only, the present study examined the expression of YB-1 in the cytoplasm and nucleus separately. The results showed that LX-2 cells treated with $960 \mathrm{mg} / \mathrm{l}$ OMT for four days exhibited a decrease of YB-1 in the cytoplasm and an increase of YB-1 in the nucleus as compared with that in the control group (Fig. 4). 

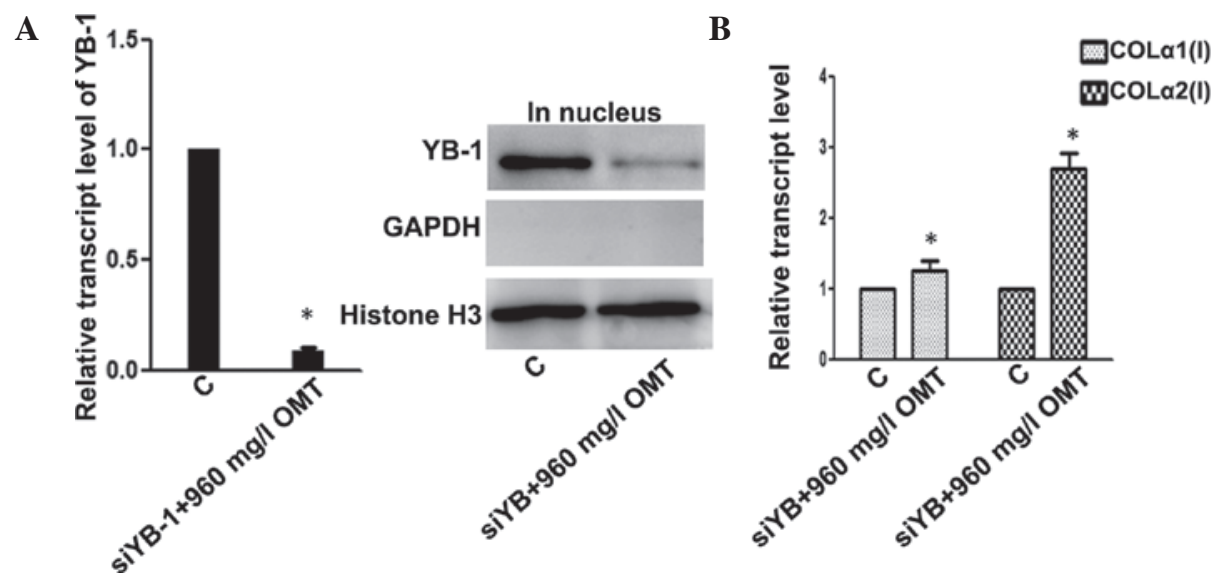

Figure 5. Depletion of YB-1 reverses the inhibitory effect of OMT on pro-collagen. (A) When LX-2 cells were treated with siYB-1 and $960 \mathrm{mg} / 1$ OMT for 4 days, the expression of YB-1 was significantly reduced at the mRNA and nuclear protein level. (B) mRNA levels of COL $\alpha 1$ (I) and COL $\alpha 2$ (I) were elevated following OMT treatment. "P<0.05 vs. C. siYB-1, small interfering RNA targeting YB-1; COL $\alpha 1(\mathrm{I})$, $\alpha 1$-strand of collagen I; OMT, oxymatrine; YB-1, Y-box binding protein $1 ; \mathrm{C}$, control.
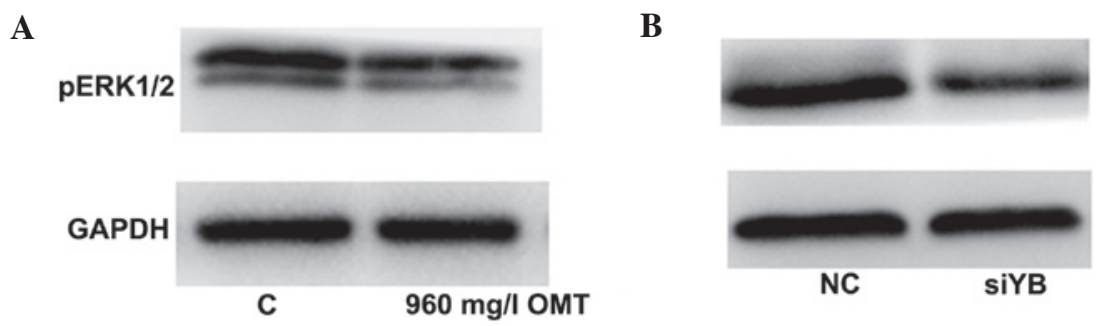

Figure 6. The ERK1/2 signaling pathway is involved in the anti-fibrotic effects of OMT-induced YB-1. (A) When LX-2 cells were only treated with $960 \mathrm{mg} / 1$ OMT for four days, the phosphorylation level of ERK1/2 protein declined. (B) With siYB-1 and $960 \mathrm{mg} / \mathrm{L}$ OMT treatment for four days, LX-2 cells showed lower expression of pERK2 (44 KDa) in comparion with the NC group ( $\mathrm{NC}+960 \mathrm{mg} / \mathrm{l} \mathrm{OMT}$ ). NC, scrambled siRNA-transfected negative control; siYB-1, siRNA targeting YB-1; YB-1, Y-box binding protein 1; C, control; OMT, oxymatrine; pERK, phosphorylated extracellular signal-regulated kinase; siRNA, small interfering RNA.

Depletion of YB-1 reverses the inhibitory effects of OMT on pro-collagen I production. In the abovementioned experiments, OMT restrained the expression of pro-collagen I, at least in part, by enhancing the nuclear translocation of YB-1. In order to further verify this mechanism, the effects of YB-1 knockdown on the expression levels of pro-collagen I were assessed. As shown in Fig. 5A, transient transfection with siYB-1 successfully knocked down YB-1. As expected, siYB-1 abrogated the inhibitory effects of OMT $(960 \mathrm{mg} / \mathrm{l})$ on pro-collagen I synthesis, as indicated by significantly elevated mRNA levels of COL $\alpha 1(\mathrm{I})$ and an even greater elevation of COL $\alpha 2$ (I) mRNA expression (Fig. 5B).

The ERK1/2 signaling pathway is involved in the anti-fibrotic effects of $Y B-1$. Since YB-1 participates in the negative regulation of fibrosis, the present study investigated the associated signaling pathways. It was found that the phosphorylation level of ERK1/2 proteins was positively associated with the changes in YB-1 expression. In the cells treated with OMT $(960 \mathrm{mg} / \mathrm{l})$, phosphorylated ERK1/2 proteins and YB-1 were declined compared to those in the control group. Furthermore, the levels of phosphorylated ERK1/2 proteins were also decreased as a result of a knockdown of YB-1 in LX-2 cells, indicating that the ERK1/2 signaling pathway have a significant role in OMT-mediated inhibition of pro-collagen I expression (Fig. 6).

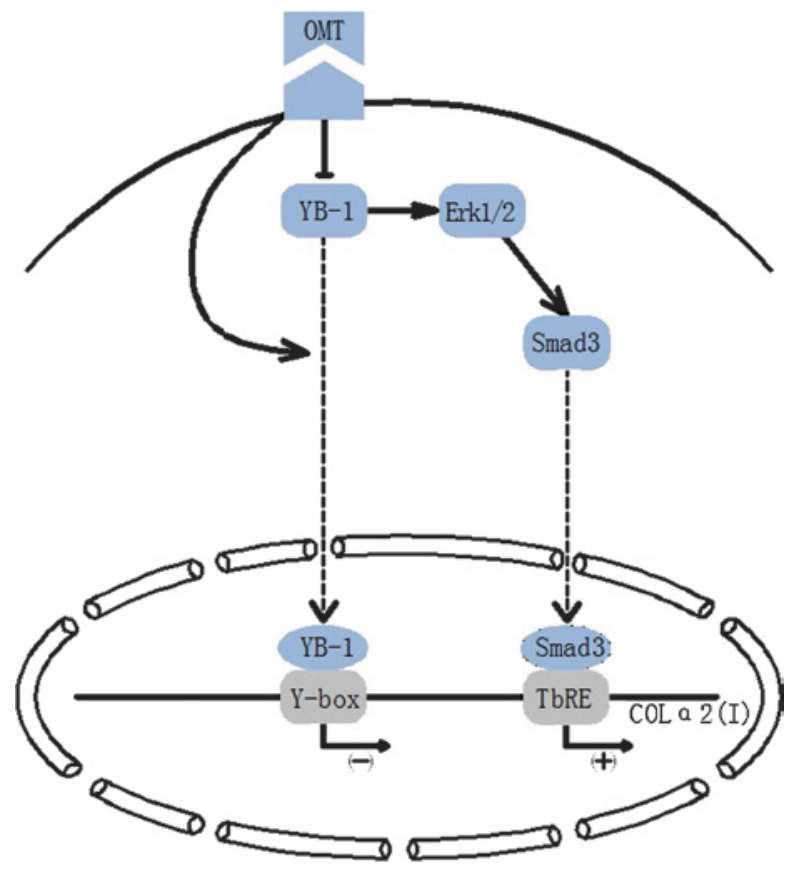

Figure 7. Attenuation of COL $\alpha 2(\mathrm{I})$ expression by OMT was, to a certain extent, mediated via nuclear translocation of YB-1. In parallel, ERK1/2 was inhibited, which indirectly affected the TGF- $\beta$ signaling pathway. YB-1, Y-box binding protein 1; OMT, oxymatrine; ERK, extracellular signal-regulated kinase; COL $\alpha 1(\mathrm{I}), \alpha 1$-strand of collagen I; TbRE, TGF- $\beta$-responsive element; TGF, transforming growth factor. 


\section{Discussion}

It is thought that patients with hepatocellular carcinoma (HCC) present with hepatitis or cirrhosis prior to developing carcinoma, with fibrosis having a central role in the pathology of all of these conditions (27). Furthermore, overexpression of YB-1, a multifunctional transcription factor, was observed in $\mathrm{HCC}$, which made it a promising prognostic biomarker used in the clinic $(28,29)$.

However, excess YB-1 can repress type I pro-collagen expression, resulting in a reduction of fibrosis. It is well known that the TGF- $\beta /$ Smad signaling pathway is implicated in pro-collagen I transcription. Furthermore, YB-1 was confirmed to be an antagonist of TGF- $\beta$, not only by inducing overexpression of Smad7, but also by inhibiting the p300-mediated activation of Smad3 and its binding to TGF- $\beta$-responsive element in the promoter of COL $\alpha 2$ (I) (16).

Although the association between OMT and downregulation of type I collagen is well established (30-32), the precise mechanism has largely remained elusive. The findings of the present study suggested that OMT stimulated the nuclear translocation of YB-1, thereby inhibiting the endogenic expression of type I pro-collagen.

It was effectively verified that OMT suppressed the expression of COL $\alpha 1(\mathrm{I})$ and COL $\alpha 2(\mathrm{I})$ genes in a dose- nd time-dependent manner. Furthermore, $\alpha$-SMA, which is expressed in activated HSCs only, was not significantly affected, indicating that OMT did not cause the recovery of the HSCs to reach the quiescent state (LX-2 is an active cell line).

Of note, the phosphorylation level of ERK1/2 proteins was positively correlated with the changes in YB-1 levels following OMT treatment. ERK1/2, members of the mitogen-activated protein kinase family, regulate diverse cellular functions, including proliferation, differentiation and cell cycle progression $(33,34)$. Studies have indicated that YB-1 activates the physiological features of certain types of cancer cell via the ERK1/2 pathway (35-37); however, its roles in fibrotic cells, such as HSCs, have remained elusive.

In addition, ERK1/2 may have interacted with the TGF- $\beta$ signaling pathway as an alternative mechanism. The functions of Smad3, the key protein in the TGF- $\beta$ signaling pathway, were shown to be ERK-dependent in certain cell types (38). Therefore, the present study hypothesized that a link exists between the YB-1-mediated regulation of the TGF- $\beta$ signaling pathway and ERK1/2.

In the present study, the total protein levels of YB-1 were decreased after OMT treatment, which was in parallel to the phosphorylation of ERK1/2. A similar result was observed after YB-1 knockdown in LX-2 cells. The appearance of only the pERK2 (44 KDa) band in the western blot may be due to the cell status during transfection.

The molecular mechanisms of the anti-fibrotic effects of OMT by facilitating the nuclear translocation of YB-1 are illustrated in Fig. 7 and can be summarized as follows: Besides directly regulating the promoter of COL $\alpha 1$ (I) and COL $\alpha 2(\mathrm{I})$ genes, YB-1 decreases the production of pro-collagen I through inhibiting the TGF- $\beta$ signaling pathway by ERK1/2.

In conclusion, OMT attenuates pro-collagen I expression, to a certain extent by increasing the levels of YB-1 in the nucleus. Furthermore, OMT is capable of mediating the inhibition of the TGF- $\beta$ signaling pathway in the presence of ERK1/2. Further study is required to completely elucidate the mechanism of action of OMT against liver fibrosis.

\section{Acknowledgements}

The present study was supported by the National Natural Science Foundation of China (grant nos. 81170405 and 81300327).

\section{References}

1. Krohn R, Raffetseder U, Bot I, Zernecke A, Shagdarsuren E, Liehn EA, van Santbrink PJ, Nelson PJ, Biessen EA, Mertens PR and Weber C: Y-box binding protein-1 controls CC chemokine ligand-5 (CCL5) expression in smooth muscle cells and contributes to neointima formation in atherosclerosis-prone mice. Circulation 116: 1812-1820, 2007.

2. Stratford AL, Habibi G, Astanehe A, Jiang H, Hu K, Park E, Shadeo A, Buys TP, Lam W, Pugh T, et al: Epidermal growth factor receptor (EGFR) is transcriptionally induced by the Y-box binding protein-1 (YB-1) and can be inhibited with Iressa in basal-like breast cancer, providing a potential target for therapy. Breast Cancer Res 9: R61, 2007.

3. Harada M, Kotake Y, Ohhata T, Kitagawa K, Niida H, Matsuura S, Funai K, Sugimura H, Suda T and Kitagawa M: YB-1 promotes transcription of cyclin D1 in human non-small-cell lung cancers. Genes Cells 19: 504-516, 2014.

4. Gaudreault I, Guay D and Lebel M: YB-1 promotes strand separation in vitro of duplex DNA containing either mispaired bases or cisplatin modifications, exhibits endonucleolytic activities and binds several DNA repair proteins. Nucleic Acids Res 32: 316-327, 2004.

5. En-Nia A, Yilmaz E, Klinge U, Lovett DH, Stefanidis I and Mertens PR: Transcription factor YB-1 mediates DNA polymerase alpha gene expression. J Biol Chem 280: 7702-7711, 2005.

6. Stein U, Jürchott K, Walther W, Bergmann S, Schlag PM and Royer HD: Hyperthermia-induced nuclear translocation of transcription factor YB-1 leads to enhanced expression of multidrug resistance-related ABC transporters. J Biol Chem 276: 28562-28569, 2001

7. Sengupta S, Mantha AK, Mitra S and Bhakat KK: Human AP endonuclease (APE1/Ref-1) and its acetylation regulate YB-1-p300 recruitment and RNA polymerase II loading in the drug-induced activation of multidrug resistance gene MDR1. Oncogene 30: 482-493, 2011.

8. Didier DK, Schiffenbauer J, Woulfe SL, Zacheis M and Schwartz BD: Characterization of the cDNA encoding a protein binding to the major histocompatibility complex class II Y box. Proc Natl Acad Sci USA 85: 7322-7326, 1988.

9. Kuwano M, Oda Y, Izumi H, Yang SJ, Uchiumi T, Iwamoto Y, Toi M, Fujii T, Yamana H, Kinoshita H, et al: The role of nuclear Y-box binding protein 1 as a global marker in drug resistance. Mol Cancer Ther 3: 1485-1492, 2004.

10. Jurchott K, Bergmann S, Stein U, Walther W, Janz M, Manni I, Piaggio G, Fietze E, Dietel M and Royer HD: YB-1 as a cell cycle-regulated transcription factor facilitating cyclin A and cyclin B1 gene expression. J Biol Chem 278: 27988-27996, 2003.

11. Eliseeva IA, Kim ER, Guryanov SG, Ovchinnikov LP and Lyabin DN: Y-box-binding protein 1 (YB-1) and its functions. Biochemistry (Mosc) 76: 1402-1433, 2011.

12. Ghiassi-Nejad Z, Hernandez-Gea V, Woodrell C, Lang UE, Dumic K, Kwong A and Friedman SL: Reduced hepatic stellate cell expression of Kruppel-like factor 6 tumor suppressor isoforms amplifies fibrosis during acute and chronic rodent liver injury. Hepatology 57: 786-796, 2013.

13. Sun W, Hou F, Panchenko MP and Smith BD: A member of the Y-box protein family interacts with an upstream element in the alpha1(I) collagen gene. Matrix Biol 20: 527-541, 2001.

14. Norman JT, Lindahl GE, Shakib K, En-Nia A, Yilmaz E and Mertens PR: The Y-box binding protein YB-1 suppresses collagen alpha $1(\mathrm{I})$ gene transcription via an evolutionarily conserved regulatory element in the proximal promoter. J Biol Chem 276: 29880-29890, 2001. 
15. Higashi K, Inagaki Y, Suzuki N, Mitsui S, Mauviel A, Kaneko H and Nakatsuka I: Y-box-binding protein YB-1 mediates transcriptional repression of human alpha 2(I) collagen gene expression by interferon-gamma. J Biol Chem 278: 5156-5162, 2003.

16. Inagaki Y, Higashiyama R and Higashi K: Novel anti-fibrotic modalities for liver fibrosis: Molecular targeting and regenerative medicine in fibrosis therapy. J Gastroenterol Hepatol 27 (Suppl 2): S85-S88, 2012.

17. Homer C, Knight DA, Hananeia L, Sheard P, Risk J, Lasham A, Royds JA and Braithwaite AW: Y-box factor YB1 controls p53 apoptotic function. Oncogene 24: 8314-8325, 2005.

18. Koike K, Uchiumi T, Ohga T, Toh S, Wada M, Kohno K and Kuwano M: Nuclear translocation of the Y-box binding protein by ultraviolet irradiation. FEBS Lett 417: 390-394, 1997.

19. Higashi K, Tomigahara Y, Shiraki H, Miyata K, Mikami T, Kimura T, Moro T, Inagaki Y and Kaneko H: A novel small compound that promotes nuclear translocation of YB-1 ameliorates experimental hepatic fibrosis in mice. J Biol Chem 286: 4485-4492, 2011.

20. Chen XS, Wang GJ, Cai X, Yu HY and Hu YP: Inhibition of hepatitis B virus by oxymatrine in vivo. World J Gastroenterol 7: 49-52, 2001.

21. Pei X, Wang W, Miao N, Xu M, Zhang C, Sun M, Xu M and Liu Z: The protective effects of the combination of sodium ferulate and oxymatrine on ethanol-induced liver damage in mice. Environ Toxicol Pharmacol 37: 423-430, 2014.

22. Zhang B, Niu W, Xu D, Li Y, Liu M, Wang Y, Luo Y, Zhao P, Liu Y, Dong M, Sun R, et al: Oxymatrine prevents hypoxia- and monocrotaline-induced pulmonary hypertension in rats. Free Radic Biol Med 69: 198-207, 2014.

23. Yang W, Zeng M, Fan Z, Mao Y, Song Y, Jia Y, Lu L, Chen CW, Peng YS and Zhu HY: Prophylactic and therapeutic effect of oxymatrine on D-galactosamine-induced rat liver fibrosis. Chinese Journal of Hepatology 10: 193-196, 2002 (In Chinese).

24. Zheng P, Niu FL, Liu WZ, Shi Y and Lu LG: Anti-inflammatory mechanism of oxymatrine in dextran sulfate sodium-induced colitis of rats. World J Gastroenterol 11: 4912-4915, 2005.

25. Dong XQ, Du Q, Yu WH, Zhang ZY, Zhu Q, Che ZH, Chen F, Wang $\mathrm{H}$ and Chen J: Anti-inflammatory effects of oxymatrine through inhibition of nuclear factor-kappa B and mitogen-activated protein kinase activation in lipopolysaccharide-induced BV2 microglia cells. Iran J Pharm Res 12: 165-174, 2013

26. Zhang J, Wang M, Zhang Z, Luo Z, Liu F and Liu J: Celecoxib derivative OSU-03012 inhibits the proliferation and activation of hepatic stellate cells by inducing cell senescence. Mol Med Rep 11: 3021-3026, 2015
27. Chemin I and Zoulim F: Hepatitis B virus induced hepatocellular carcinoma. Cancer Lett 286: 52-59, 2009.

28. Tacke F, Kanig N, En-Nia A, Kaehne T, Eberhardt CS Shpacovitch V, Trautwein C and Mertens PR: Y-box protein-1/p18 fragment identifies malignancies in patients with chronic liver disease. BMC Cancer 11: 185, 2011.

29. Yasen M, Kajino K, Kano S, Tobita H, Yamamoto J, Uchiumi T, Kon S, Maeda M, Obulhasim G, Arii S and Hino O: The up-regulation of Y-box binding proteins (DNA binding protein $\mathrm{A}$ and Y-box binding protein-1) as prognostic markers of hepatocellular carcinoma. Clin Cancer Res 11: 7354-7361, 2005.

30. Chai NL, Fu Q, Shi H, Cai CH, Wan J, Xu SP and Wu BY: Oxymatrine liposome attenuates hepatic fibrosis via targeting hepatic stellate cells. World J Gastroenterol 18: 4199-4206, 2012.

31. Chen X, Sun R, Hu J, Mo Z, Yang Z, Liao D and Zhong N: Attenuation of bleomycin-induced lung fibrosis by oxymatrine is associated with regulation of fibroblast proliferation and collagen production in primary culture. Basic Clin Pharmacol Toxicol 103: 278-286, 2008

32. Huang XY and Chen CX: Effect of oxymatrine, the active component from Radix Sophorae flavescentis (Kushen), on ventricular remodeling in spontaneously hypertensive rats. Phytomedicine 20: 202-212, 2013.

33. Raman M, Chen W and Cobb MH: Differential regulation and properties of MAPKs. Oncogene 26: 3100-3112, 2007.

34. Yoon S and Seger R: The extracellular signal-regulated kinase: Multiple substrates regulate diverse cellular functions. Growth Factors 24: 21-44, 2006.

35. Imada K, Shiota M, Kohashi K, Kuroiwa K, Song Y, Sugimoto M, Naito $S$ and Oda Y: Mutual regulation between Raf/MEK/ERK signaling and Y-box-binding protein-1 promotes prostate cancer progression. Clin Cancer Res 19: 4638-4650, 2013.

36. Lee C, Dhillon J, Wang MY, Gao Y, Hu K, Park E, Astanehe A, Hung MC, Eirew P, Eaves CJ and Dunn SE: Targeting YB-1 in HER-2 overexpressing breast cancer cells induces apoptosis via the mTOR/STAT3 pathway and suppresses tumor growth in mice. Cancer Res 68: 8661-8666, 2008

37. Zhao BX, Sun YB, Wang SQ, Duan L, Huo QL, Ren F and Li GF: Grape seed procyanidin reversal of p-glycoprotein associated multi-drug resistance via down-regulation of NF- $\kappa \mathrm{B}$ and MAPK/ERK mediated YB-1 activity in A2780/T cells. PLoS One 8: e71071, 2013.

38. Hayashida T, Decaestecker M and Schnaper HW: Cross-talk between ERK MAP kinase and Smad signaling pathways enhances TGF-beta-dependent responses in human mesangial cells. FASEB J 17: 1576-1578, 2003. 